Egyptian

Orthodontic Journal

\title{
THE INFLUENCE OF ETHANOL-BASED ADHESIVE ON THE SHEAR BOND STRENGTH OF ORTHODONTIC BRACKETS BONDED TO BLEACHED ENAMEL
}

\author{
Essam A Nassar*, Abeer E El- Embaby ${ }^{*}$ \\ Mahasen Taha ${ }^{* * *}$
}

ABSTRACT:

Tooth 6leaching is one of the modern cosmetic approaches in dentistry. The aim of this study was to evaluate the effect of ethanol-6ased adhesive (ExciTE®), Ivoclar Vivadent, Liechtenstein, Germany) application on the shear bond strength of orthodontic brackets bonded immediately to the teeth after vital bleaching. The study was carried out on 45 human premolars. The teeth were randomly divided into 3 groups, group 1(control group), group 2 (bleach only) and group three (bleach d L Exciteß). All the brackets were bonded with Transbond XT light cured composite (Unitek 3M, Monrovia, Calif). Universal testing machine was used to measure the immediate shear 6ond strength. Results of this study showed that, the mean values of the shear bond strengths were 12.1 Mpa, 3.9 Mpa and 11.6 Mpa for groups 1, 2 and 3 respectively. There was a significant difference between the three tested groups $(p<0.05)$. There was a significant difference between group 1 and 2, also between group 2 and group $3(p<0.05)$. On the other hand, there was no significant difference between group 1 and $3(p>0.05)$.

It was concluded that application of ethanol- based adhesive (ExciTE ${ }^{\circledR}$ ) after 6leaching could enhance the immediate 6ond strength of orthodontic brackets bonded to enamel surface.

\footnotetext{
* Lecturer, Department of Orthodontics, Mansoura University, Faculty of Dentistry, Egypt.

** Lecturer,Department of Conservative Dentistry, Mansoura University, Faculty of Dentistry, Egypt.

${ }^{* * * *}$ Lecturer, Department of Orthodontics, Mansoura University, Faculty of Dentistry, Egypt.
} 
Egyptian

Orthodontic Journal

\section{INTRODUCTION}

Recently, tooth whitening has become more popular; fulfilling patient demands for both healthy and cosmetically attractive smiles. ${ }^{(1)}$ Tooth bleaching is considered to be an effective and non aggressive treatment. ${ }^{(2)}$

There are three basic bleaching approaches: dentist-supervised night guard vital bleaching or home bleaching; in-office or power bleaching; and over- thecounter bleaching products. ${ }^{(3)}$ The hydrogen peroxide (HP) and carbamide peroxide $(\mathrm{CP})$ solutions are two of the most commonly used bleaching agents. ${ }^{(4)}$

Generally, in-office bleaching is done with high concentrations of hydrogen peroxide (25\%-35\%), a heat source, and a rubber dam to protect the gingival tissues. ${ }^{(5)}$ In contrast, home bleaching usually uses low concentration of bleaching agent, applied to the teeth by a fabricated custom tray. ${ }^{(2)}$

Previous studies have shown that hydrogen peroxide and carbamide peroxide used as bleaching agents affect the bond strength of composite to acid etched enamel when bonding was performed immediately after the bleaching treatment. ${ }^{(4,6,7,8)}$ Residual bleaching agents might affect the bonding process and were responsible for decreased bond strengths. Delaying the whitening regime until the completion of orthodontic treatment was suggested to overcome the reduction in bond strength. ${ }^{(4)}$

Treating of the bleached enamel surface with $10 \%$ sodium ascorbate was found to reverse the decreased bond strength and there was no significant difference between its bond strength's values and those of the immersed samples in the artificial salvia. Authors recommended use of $10 \%$ sodium ascorbate after bleaching and before bonding the orthodontic attachments. ${ }^{(9)}$

On the other hand, it was concluded that, only catalase application resulted in significant increase of bond strength of the composite cylinders bonded to bovine teeth than the bleached group. Either10\% sodium ascorbate, acetone, ethanol, sodium bicarbonate, or glutathione peroxidase showed no significant difference compared to the bleached group. None of the previous treatments was able to neutralize the deleterious effects of bleaching on the bond strength completely. ${ }^{(10)}$ However, catalase substance is very unstable, loosing quickly its activity and is costly high.

The aim of this study was to determine the effect of ethanol-based adhesive $\left(\right.$ Excite $\left.^{\circledR}\right)$ application on the immediate shear bond strength of orthodontic brackets bonded to the enamel surface after vital bleaching. 
Egyptian

Orthodontic Journal

\section{Materials and Methods:}

The sample of this study consisted of 45 sound freshly extracted human permanent premolar teeth. The teeth were collected and stored in a solution of $0.1 \%$ thymol at room temperature for one week. The collected teeth were examined under a light stereomicroscope at ten times magnification, all the samples must be free from any caries or cracks and have intact enamel surface, and then the samples were stored in distilled water until required. The water was changed weekly to avoid bacterial growth. ${ }^{11}$ The teeth were randomly divided into three groups $(1,2$, and 3 ) each of 15 teeth. Each tooth was sectioned and the crown portion was mounted in a self cure acrylic resin so that the buccal surface was exposed. The teeth were cleansed and polished with pumice and rubber cups for 10 seconds and washed with water. Fourty five edgewise stainless steel brackets (Dentaurum, Germany; No: 713-022-50) were bonded according the following protocols:

Group 1 (control): Teeth were etched with $38 \%$ phosphoric acid etching gel (Etch-rite, Pulpdent Corporation, Watertown, MA 02471, USA) for 20 seconds. The teeth were then rinsed with water for 20 seconds and air dried for 30 seconds. The stainless steel brackets were bonded on the buccal surface with a light activated orthodontic adhesive Transbond XT (Unitek 3M, Monrovia, Calif) following manufacture's instructions. The composite was cured using LED (Light Emitting Diode) curing unit (SLC-VI, Hang Zhou Sifang Medical Apparatus, Hang zhou/Zhejiang, China). All brackets were exposed 40 seconds for the light, 10 seconds at each side (mesial, distal, occlusal and gingival). ${ }^{(12)}$

Group 2 (bleach only): The teeth were bleached using 16\%wt carbamide peroxide (SDI polanight bleaching gel, SDI, Bensenville, IL, USA). The bleaching agent was painted on the top surface of the specimen according to the manufacturer's instructions at room temperature for 8 hours per day for 14 days to simulate the bleaching course. After bleaching, the specimens were rinsed with tap water for 1 minute to remove the bleaching agent, and stored in artificial saliva for 16 hours per day for the 14 days of the bleaching course to simulate the oral environment. Etching and bonding the brackets to the teeth were done as in group 1.

Group 3 (bleach \& ExciTE $^{\circledR}$ ): Bleaching protocol was done similar to group 2, teeth were etched with 38\% phosphoric acid etching gel for 20 seconds, then rinsed with water for 20 seconds and air dried for 30 seconds. The surface was saturated with a generous amount of ExciTE $^{\circledR}$ (Ivoclar Vivadent, Liechtenstein, Germany) instead of Transbond XT primer and the adhesive on 
the surface was gently agitated for at least 10 seconds. Any excess was removed by a gentle stream of air for 3 seconds. Then the adhesive was light cured for 10 seconds according to the manufacture's instructions. Bonding of orthodontic brackets with Transbond XT composite was done similar to the group 1.

The shear bond strength of each sample was tested with a universal testing machine (LLOYD, England). The sample was attached to the lower part of the testing machine. The shear force was applied via the upper part of the testing machine parallel to the long axis of the tooth at a crosshead speed of 0.5 $\mathrm{mm} / \mathrm{min}$ (Figure 1). The load required to debond the brackets were measured in Newtons $(\mathrm{N})$. The shear bond strength was obtained in Mpa using the equation:

Shear bond strength $(\mathrm{Mpa})=$ load $(\mathrm{N}) \div$ surface area of the bracket $\left(\mathrm{mm}^{2}\right)$.

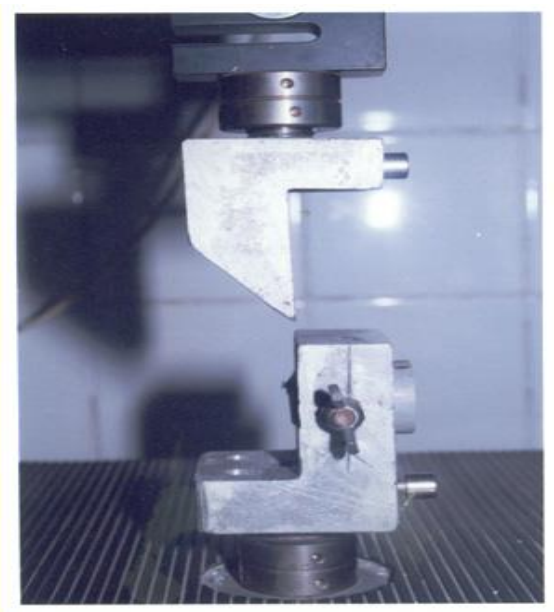

Figure 1: The sample attached to the lower part of the testing machine.

\section{Statistical analysis:}

All the collected data were analyzed using SPSS program and the descriptive statistics including the mean, standard deviation, minimum and maximum values were obtained. One way analysis of variance (ANOVA) was done to test a significant difference between the different groups. Post hoc Scheffé test compared the difference between the tested groups at the 5\% level of significance. 


\section{RESULTS}

The means, standard deviations, standard errors, minimum and maximum values of the shear bond strengths are shown in table I and figure 2. The mean shear bond strength of the control group was $12.31 \mathrm{Mpa}$, group 2 was $3.93 \mathrm{Mpa}$, and group 3 was $11.61 \mathrm{Mpa}$. Results of ANOVA test (table II) showed a significant difference between the tested groups $\mathrm{p}<0.05$. Post hoc Scheffé test (table III) showed no significant difference between group 1 and group 3 (p>0.05). There was a significant difference between group 1 and 2 and between group 2 and $3(\mathrm{p}<0.05)$.

Table I: Means, standard deviations, standard errors, upper and lower bound values of the shear bond strength (Mpa) of the tested groups.

\begin{tabular}{|l|c|c|c|c|c|c|}
\hline & N & Mean & Std. Deviation & Std.Error & $\begin{array}{c}\text { Lower } \\
\text { Bound }\end{array}$ & $\begin{array}{c}\text { Upper } \\
\text { Bound }\end{array}$ \\
\hline Group 1 & 15 & 12.11 & 1.71 & 0.444 & 11.16 & 13.06 \\
\hline Group 2 & 15 & 3.93 & 0.753 & 0.194 & 3.5 & 4.3 \\
\hline Group 3 & 15 & 11.61 & 1.67 & 0.432 & 10.6 & 12.5 \\
\hline Total & 45 & & 4.04 & 0.602 & & \\
\hline
\end{tabular}

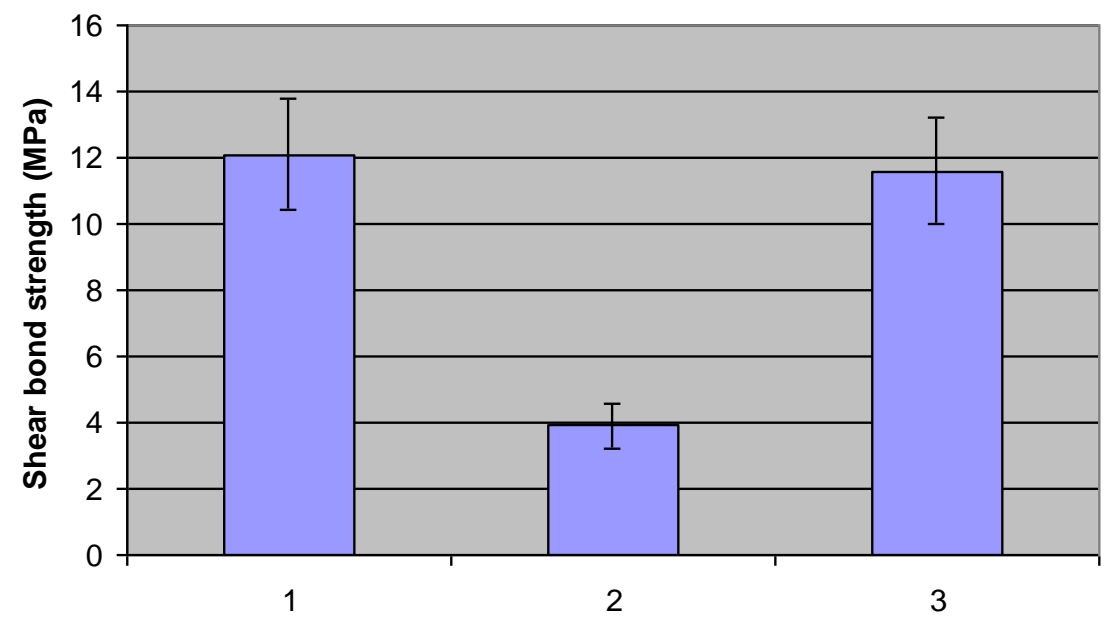

Figure 2. Means and standard deviations of the three tested groups. 
Egyptian

Orthodontic Journal

Table II: One way analysis of variance (ANOVA) showing a significant difference between the tested groups.

\begin{tabular}{|l|c|c|c|c|c|}
\hline \multicolumn{1}{|c|}{ Source } & Sum of squares & df & Mean square & f & Significance \\
\hline Between groups & 630.7 & 2 & 315.3 & 149 & 0.000 \\
\hline Within Groups & 88.5 & 42 & 2.10 & & \\
\hline Total & 719.2 & 44 & & & \\
\hline
\end{tabular}

Significant at $\mathrm{p}<0.05$.

Table III: Post hoc Scheffé multiple comparisons of the three tested groups.

\begin{tabular}{|c|c|c|c|c|c|c|}
\hline \multirow{2}{*}{\multicolumn{2}{|c|}{$\begin{array}{l}\text { (I) Group (J) } \\
\text { Group }\end{array}$}} & \multirow{2}{*}{$\begin{array}{c}\text { Mean } \\
\text { Difference } \\
\text { (I-J) }\end{array}$} & \multirow{2}{*}{$\begin{array}{c}\text { Std. } \\
\text { Error }\end{array}$} & \multirow[t]{2}{*}{ Sig } & \multicolumn{2}{|c|}{ 95\% confidence interva } \\
\hline & & & & & $\begin{array}{l}\text { Lower } \\
\text { bound }\end{array}$ & $\begin{array}{l}\text { Upper } \\
\text { bound }\end{array}$ \\
\hline \multirow[t]{2}{*}{1} & 2 & 8.18 & 0.530 & 0.000 & 6.83 & 9.52 \\
\hline & 3 & 0.50 & 0.530 & 0.644 & -0.846 & 1.84 \\
\hline 2 & 3 & -7.68 & 0.530 & 0.000 & -9.02 & -6.33 \\
\hline
\end{tabular}

Significant at $p<0.05$.

\section{DISCUSSION}

Adult orthodontic patients may not be satisfied only with well-aligned teeth, but also requesting white teeth. Discoloration of teeth is one of the major esthetic challenges. Stains might be due to either intrinsic or extrinsic factors. ${ }^{(13)}$ Bleaching treatment has been considered to be non invasive approach to achieving white teeth.

Contemporary tooth bleaching systems are based primarily on hydrogen peroxide (HP) or one of its precursors notably, carbamide peroxide (CP). CP is a chemical adduct of urea and HP, which upon dissolving in water or saliva disassociates back into HP and urea. ${ }^{(14)}$

There is a big controversy about the effect of bleaching on the bond strength to the enamel. Some authors founded that, in-office bleaching with $35 \%$ hydrogen peroxide did not affect the bond strengths of brackets immediately after bleaching. Furthermore, immersing bleached teeth in artificial saliva for 30 days, did not significantly affect the bond strength. ${ }^{(11)}$ 
In contradictory, bleaching had been found to affect the bond strength of composite to acid etched enamel when bonding is performed immediately after the bleaching treatment ${ }^{(6,7)}$. Authors suggested discontinuing tooth whitening product usage from 1 to 3 weeks before bonding to the enamel. ${ }^{(8,15)}$

ExciTE $^{\circledR}$ (ethanol- based adhesive) contains $19.5 \%$ wt ethanol, was selected in this study among other adhesives, since the effect of bonding agent usage on the bond strength of composite cylinders bonded to bleached enamel was found to be dependent on the type of solvent in the bonding agent. There was no statistical significant difference between ethanol based adhesive aided bond strength for bleached and un-bleached enamel. While, bond strength of composite to bleached enamel bonded with acetone based adhesive showed a significant difference to the un-bleached enamel. ${ }^{(16)}$

It had been shown that, after bleaching; the residual oxygen penetrated and concentrated on the enamel surface causing inhibition in the polymerization of the resin tags. Alcohol ingredient in the adhesive could interact with the residual oxygen and minimize this inhibitory effect. ${ }^{(17)}$

Results of this study showed that, tooth bleaching significantly, reduced the immediate bond strength $\mathrm{p}<0.05$. These finding were in agreement with previous findings. ${ }^{(6,7,8)}$ Integrity of tooth structure might be influenced as a result of bleaching. This influence might result in a decrease of the calcium and phosphate content, and also the fluoride enamel. ${ }^{(18,19)}$ Additionally. changes of the surface texture after application of bleaching gels are described as topographical alterations, decalcification, and porosities in enamel. ${ }^{(20,21)}$ Meanwhile; these results disagreed with other studies which reported that, bleaching had no adverse on the bond strength. ${ }^{(5,11)}$

Findings of this work declared also that, there was no significant difference between the bleached \& ExciTE $^{\circledR}$ treated group and the control group $p>0.05$. Such findings indicating that the ExciTE ${ }^{\circledR}$ neutralized the bleaching effect completely. Furthermore, there was a significant difference between these values and the bleached group's values.

The neutralizing effect of the ethanol could be attributed to the fact that bleached enamel is more porous and therefore, has more water containing oxygen; the high pressure solvents are able to displace the water and to improve the impregnation of the dental substrate. ${ }^{(17)}$ Additionally, interaction of the organic solvents with the free radicals found in the enamel resulting in their inactivation. ${ }^{(22)}$ 
Egyptian

Orthodontic Journal

\section{CONCLUSION}

Addition of the ethanol-based adhesive (ExciTE ${ }^{\circledR}$ ) to the bleached enamel surface improved the bond strength and rendered immediate bonding more possible.

\section{REFERENCES}

1. Joiner A, Thakker J, Cooper Y. Evaluation of a $6 \%$ hydrogen peroxide tooth whitening gel on enamel and dentin microhardness in vitro. J Dent 2004; $32: 27-34$

2. Haywood VB, Heymann HO. Nightguard vital bleaching: how safe is it? Quint Int 1991; 22:515-23.

3. Heymann HO. Tooth whitening: facts and fallacies. British Dent J. 2005; 198:514.

4. Türkkahraman H, Adanir N, Güngör AY. Bleaching and desinsitizer application effects on shear bond strengths of orthodontic brackets. Angle orthod 2007; 77:489-93.

5. Bishara SE, Oonsombat C, Soliman MM, Ajlouni R, Laffoon JF. The effect of tooth bleaching on the shear bond strength of orthodontic brackets. Am J Orthod Dentofacial Orthop 2005; 128:755-60.

6. Titley KC, Torneck CD, Smith DC, Abdifar A. Adhesion of composite resin to bleached and unbleached bovine enamel. J Dent Res 1988; 67:1523-8.

7. Garcia-Godoy F, Dodge WW, Donohue M, O, Quinn JA. Composite resin bond strength after enamel bleaching. Oper Dent 1993; 18:144-7.

8. Miles PG, Pointer JP, Bahiraei D, Close J. The effect of carbamide peroxide bleach on the tensile bond strength of ceramic brackets: an in vitro study. Am J Orthod Dentofacial Orthop 1994; 106:371-75.

9. Bulut H, Kaya AD, Turkun M. Tensile bond strength of brackets after antioxidant treatment on bleached teeth. Eur J Orthod 2005; 27:466-71.

10. Torres CRG, Koga AF, Borges AB. The effects of anti-oxidant agents as neutralizers of bleaching agents on enamel. Braz J Oral Sci 2006; 5:971- 76.

11. Uysal T, Basciftci FA, Usumez S, Sari Z, Buyukerkmen A. Can previously bleached teeth bonded safely? Am J Orthod Dentofacial Orthop 2003; 123:628-32. 
12. Cacciafesta V, Sfondrini MF, Stifanelli P,Scribante A, Klersy C. The effect of bleaching on shear bond strength of brackets bonded with a resin modified glass ionomer. Am J Orthod Dentofacial Orthop 2006;130:83-7.

13. Sulieman M. An overview of tooth discoloration: extrinsic, intrinsic, and internalized stains. Dent Update 2005; 32:463-68.

14. Joiner A. Review of the effects of peroxide on enamel and dentin properties of Dent 2007; 889-96.

15. Dishman MV, Covey DA, Baughan LW. The effects of peroxide bleaching on composite to enamel bond strength. Dent Mater 1994; 9:33-6.

16. Sung EC, Chan SM, Mito R, Caputo AA. Effect of carbamide peroxide bleaching on the shear bond strength of composite to dental bonding agent enhanced enamel. J Prosthet Dent 1999; 82:595-9

17. Kalili T, Caputo AA, Mito R, Sperbeck G, Matyas J. In vitro toothbrush abrasion and bond strength of bleached enamel. Pract Period Aesth Dent 1991; 3:22-4.

18. McCracken MS, Haywood VB. Demineralization effects of 10 percent carbamide peroxide. J of Dent 1996; 24-395-8.

19. Burgmaier Gm, Schulze IM, Attin T. Fluoride uptake and development of artificial erosions in bleached and fluoridated enamel in vitro. J Oral Rehabil 2002; 29:799-04.

20. McGuchin RS, Babin JF, Meyer BJ. Alterations in human enamel surface morphology following vital bleaching. J Prosthet Dent 1992;68:754-60.

21. Shannon H, Spencer P, Gross K, Tira D.Characterization of enamel exposed to $10 \%$ carbamide peroxide bleaching agents. Quint Int 1993;24:39-44.

22. Perdigao J, Francci C, Swift EJJr, Ambrose WW, Lopes M. Ultra - morphological study of the interaction of dental adhesives with carbamide peroxide-bleached enamel. Am J Dent 1998; 11:291-301. 